\title{
Attenuation of Focal Ischemic Brain Injury in Mice Deficient in the $\epsilon 1$ (NR2A) Subunit of NMDA Receptor
}

\author{
Eiharu Morikawa, ${ }^{1,3,4}$ Hisashi Mori, ${ }^{2}$ Yuji Kiyama, ${ }^{2}$ Masayoshi Mishina, ${ }^{2,4}$ Takao Asano, ${ }^{3}$ and Takaaki Kirino ${ }^{1,4}$ \\ Departments of ${ }^{1}$ Neurosurgery and ${ }^{2}$ Molecular Neurobiology and Pharmacology, University of Tokyo Faculty of Medicine, \\ Bunkyo-ku, Tokyo 113-8655, Japan, ${ }^{3}$ Department of Neurosurgery, Saitama Medical School/Center, Kawagoe, Saitama \\ 350-8550, Japan, and ${ }^{4}$ Core Research for Evolution and Technology, Japan Science and Technology Corporation, \\ Kawaguchi, 332-0012, Japan
}

The role of glutamate neurotoxicity in cerebral ischemia has long been advocated but still remains controversial, because various glutamate receptor (GluR) antagonists showed inconsistent protective efficacy in brain ischemia models. To address this central issue of ischemic brain damage more directly, we used mutant mice deficient in the GluRe1 (NR2A) subunit of NMDA receptor with or without additional heterozygous mutation in the GluR $\epsilon 2$ (NR2B) subunit. Those mutant mice, as well as their littermates, were subjected to focal cerebral ischemia by introducing a 6-0 nylon suture from left common carotid artery. Brain injury volumes after $2 \mathrm{hr}$ of suture insertion, as evaluated by 2,3,5-triphenyltetrazolium chloride staining at 24 hr after ischemia, revealed significantly smaller injury size in GluR $\epsilon 1$ subunit knock-out mice compared with their wild-type littermates. The reduction in injury volume was not attributable to differences in body temperature or in blood flow during ischemia. Additional heterozygous GluRe2 subunit disruption did not result in further reduction in injury volume. These data directly demonstrate relevance of NMDA receptor-mediated tissue injury after brain ischemia and provide evidence that GluR $\epsilon 1$ subunit is involved in these injurious mechanisms.

Key words: NMDA receptor; GluRe1 subunit; neurotoxicity; glutamate; brain ischemia; cerebral infarction
Brain ischemia causes massive elevation of extracellular glutamate concentration. An excess amount of glutamate is postulated to induce glutamate receptor (GluR)-mediated cascade reactions, which eventually lead to brain damage (Choi, 1988; Lipton and Rosenberg, 1994). Molecular cloning studies have identified five NMDA receptor subunits called GluR $\zeta 1$ (NR1) and GluR $\epsilon 1-$ GluRe4 (NR2A-NR2D) (Nakanishi, 1992; Seeburg, 1993, Mori and Mishina, 1995). Among these five subunits, GluR $\zeta 1$, GluR $\epsilon 1$ (NR2A), and GluRe2 (NR2B) are the major components of the hetero-oligomeric NMDA receptor channel complex distributed in the mature forebrain (Watanabe et al., 1992). The GluR $\zeta 1$ and GluRe2 subunits are the constituents of the receptor molecule during stages of embryonic development. Mice with a null mutation in the GluR $\zeta 1$ or the GluR $\epsilon 2$ subunit gene die shortly after birth and have a defect in the formation of neuronal pattern in the brainstem (Forrest et al., 1994; Li et al., 1994; Kutsuwada et al., 1996). In contrast, GluR $\epsilon 1$ subunit is expressed only in the postnatal brain, and mice lacking the gene for this subunit $\left(\epsilon 1^{-/-}\right)$ develop and mate normally. Detailed electrophysiological and behavioral evaluation, however, has revealed that the GluRe1 subunit knock-out $(\epsilon 1 \mathrm{KO})$ mice have reduced hippocampal longterm potentiation (LTP) and impaired spatial and contextual learning, which confirms that disruption of this gene disturbs normal NMDA receptor functions (Sakimura et al., 1995; Kiyama et al., 1998). We subjected these mice to focal cerebral

Received May 7, 1998; revised Sept. 21, 1998; accepted Sept. 22, 1998.

This work was supported in part by a Grant-in-Aid for Scientific Research from the Ministry of Education, Science, and Culture of Japan. We thank Dr. Keisuke Ueki for helpful comments and advice and Dr. Nobuto Saito for technical assistance.

Correspondence should be addressed to Dr. Takaaki Kirino, Department of Neurosurgery, University of Tokyo Faculty of Medicine, 7-3-1 Hongo, Bunkyo-ku, Tokyo 113-8655, Japan.

Copyright (C) 1998 Society for Neuroscience $\quad 0270-6474 / 98 / 189727-06 \$ 05.00 / 0$ ischemia to investigate the significance of the GluR $\epsilon 1$ subunit of NMDA receptor in the development of tissue injury after brain ischemia. Furthermore, we mated these $\epsilon 1 \mathrm{KO}$ mice with other genetically engineered mice harboring a heterozygous GluR $\epsilon 2$ mutation $\left(\epsilon 1^{+/+} \epsilon 2^{+/-}\right.$, Kutsuwada et al., 1996) to create mice with both a null mutation in the GluR $\epsilon 1$ gene and a heterozygous mutation in the GluR $\epsilon 2$ gene $\left(\epsilon 1^{-/-} \epsilon 2^{+/-}, \epsilon 1 \mathrm{KO} \epsilon 2 \mathrm{H}\right)$. To study the significance of the remaining GluR $\epsilon 2$ subunit in $\epsilon 1 \mathrm{KO}$ mice, we also evaluated the development of ischemic brain injury in these double-mutant mice.

\section{MATERIALS AND METHODS}

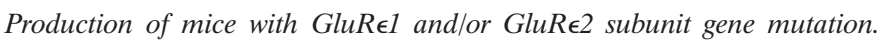
Generation and characterization of the GluR $\epsilon 1$ subunit knock-out (Sakimura et al., 1995) and GluRe2 subunit knock-out (Kutsuwada et al., 1996) in TT2 embryonic stem cells, followed by back-crossing with C57BL/6 mice, have been described elsewhere. Mice with GluR $\epsilon 1$ homozygous and GluR $\epsilon 2$ heterozygous mutation were produced by mating the homozygous GluR $\epsilon 1$ mutant mice $\left(\epsilon 1^{-/-} \epsilon 2^{+/+}\right)$with GluR $\epsilon 2$ heterozygous mutant mice $\left(\epsilon 1^{+/+} \epsilon 2^{+/-}\right)$. The resultant heterozygous mutants for both GluR $\epsilon 1$ and GluR $\epsilon 2\left(\epsilon 1^{+/-} \epsilon 2^{+/-}\right)$were crossed with GluR $\epsilon 1$ homozygous mutants $\left(\epsilon 1^{-/-} \epsilon 2^{+/+}\right)$to generate GluR $\epsilon 1$ homozygous and GluR $\epsilon 2$ heterozygous mutant mice $\left(\epsilon 1^{-/-} \epsilon 2^{+/-}\right)$. The offspring mice $\left(\epsilon 1^{-/-} \epsilon 2^{+/-}\right)$were mated again with GluR $\epsilon 1$ homozygous mutants $\left(\epsilon 1^{-l-} \epsilon 2^{+/+}\right)$to expand the colony of GluR $\epsilon 1$ homozygous and GluR $\epsilon 2$ heterozygous mutant mice $\left(\epsilon 1^{-/-} \epsilon 2^{+/-}\right)$and homozygous mutant mice for GluR $\epsilon 1\left(\epsilon 1^{-/-} \epsilon 2^{+/+}\right)$.

Western blot analysis of GluRe1 and GluRe2 subunit proteins in the forebrain. Western blot analysis was done essentially as described previously (Sakimura et al., 1995; Takahashi et al., 1996; Watanabe et al., 1998). In brief, the wild-type (WT) and mutant mice were decapitated under anethesia, and each forebrain was removed rapidly and homogenized. The proteins $(100 \mathrm{mg})$ prepared from each forebrain homogenate were fractionated by SDS-PAGE and electroblotted onto a nitrocellulose membrane. The blots were immunoreacted with anti-GluR $\epsilon 1$, anti- 
GluR $\epsilon 2$, or anti-neuron-specific enolase (NSE) antibody, and the protein bands were visualized by chemiluminescence (ECL detection system; Amersham, Arlington Heights, IL). The rabbit anti-GluRe1, antiGluR $\epsilon$, and anti-NSE antibodies were prepared previously (Sakimura et al., 1980, 1995; Watanabe et al., 1998). For quantitative analysis, the immunoreactive bands were scanned using a computing densitometry and analyzed with NIH Image software (version 1.58). The quantity of the immunoreactive bands of GluR $\epsilon 1$ and GluR $\epsilon 2$ proteins were corrected by comparing them with the band of NSE protein as an internal standard for the amount of protein loaded onto the gels.

Production of focal cerebral ischemia. Nonfasted mice of either sex were subjected to cerebral ischemia by an investigator (E.M.) blinded to the group identity. Anesthesia was induced and maintained by halothane ( 3 and $1 \%$, respectively) plus $50 \%$ nitrous oxide and the balance of oxygen under spontaneous ventilation. Because repeated blood withdrawal from mice was not compatible with further ischemia experiments, the samples for physiological data (arterial $\mathrm{pO}_{2}, \mathrm{pCO}_{2}, \mathrm{pH}$, and blood glucose) were taken from a separate set of animals $(n=5$ each $)$. These physiological parameters were maintained within normal range under the setting of ischemia induction, and there were no differences between the groups. Focal cerebral ischemia was produced as described previously (Huang et al., 1994). After ligation of the left proximal common carotid artery, a 6-0 nylon monofilament (Ethilon; Ethicon, Inc., Somerville, NJ) with a heat-modified head was introduced into the distal internal carotid artery and was advanced $\sim 11 \mathrm{~mm}$ distal to the carotid bifurcation. The filament was wedged into the circle of Willis, producing focal cerebral ischemia in the left middle cerebral artery territory. The wound was closed, and the animal was returned to its cage. In transient focal cerebral ischemia, the nylon filament was withdrawn from the carotid artery $2 \mathrm{hr}$ after insertion under halothane anesthesia. During the surgical procedure, the rectal temperature was kept normothermic $\left(36.5-37.5^{\circ} \mathrm{C}\right)$ by a heating pad and a heating lamp (ATB-1100; Nihon Koden, Tokyo, Japan).

Evaluation of tissue injury after ischemia. Twenty-four hours after arterial occlusion, the mice were anesthetized with 3\% halothane and decapitated. Brains were removed immediately and placed in ice-cold saline for $10 \mathrm{~min}$ and sectioned coronally into 5 slices (2-mm-thick) in a rodent brain matrix (Mouse Brain Slicer; Medical Agent Co. Ltd., Tokyo, Japan). Brain slices were placed in 2\% 2,3,5-triphenyltetrazolium chloride monohydrate (TTC) (Sigma, St. Louis, MO) at room temperature for $30 \mathrm{~min}$ (Bederson et al., 1986), followed by $10 \%$ formalin overnight. Brain slices were directly scanned on an image scanner (JX320M; Sharp, Tokyo, Japan). The area of ischemic injury was measured (NIH Image software) on the posterior surface of each section. The injury volume was calculated by numeric integration of the sequential areas. Eight mice could not survive for $24 \mathrm{hr}$ after ischemia. Because exclusion of these mice could affect overall effects of the gene mutation on the ischemic injury, the brains of those animals were removed as soon as the animal's death was confirmed, and the size of the brain injury was evaluated by the same method as above.

Genotyping of mice by Southern blot hybridization analysis. Genotyping of the mice that were used for the brain injury analysis was done in a completely blind manner by another investigator (H.M.). Genotype of each mouse was identified by Southern blot hybridization analysis of the genomic DNA extracted from tail specimen taken at the time of death as described above. In brief, Southern blot hybridization analysis of the GluR $\epsilon 1$ locus was done using BamHI-digested tail DNA hybridized with a $1.2 \mathrm{~kb}$ SmaI-SmaI fragment of the GluR $\epsilon 1$ gene (Sakimura et al., 1995). Southern blot hybridization analysis of the GluR $\epsilon 2$ locus was performed using EcoRI-digested tail DNA hybridized with a $0.4 \mathrm{~kb} H$ HindIII-XbaI fragment of the GluR $\epsilon 2$ gene (Kutsuwada et al., 1996).

Evaluation of regional cerebral blood flow by laser-Doppler flowmetry. Under halothane anesthesia with spontaneous ventilation as described above, regional cerebral blood flow $(\mathrm{CBF})$ at dorsolateral cerebral cortex was determined by laser-Doppler flowmetry (LBF-IIIF; Biomedical Science, Tokyo, Japan) as demonstrated previously (Morikawa et al., 1996). After exposing and thinning the skull at $1 \mathrm{~mm}$ posterior and $4 \mathrm{~mm}$ lateral to the bregma, the head of the mouse was fixed in a stereotaxic frame (Narishige, Tokyo, Japan) in supine position, and the tip of the flowmetry probe $(0.8 \mathrm{~mm}$ in diameter $)$ was secured perpendicular to the skull surface. After baseline measurements were obtained, the left common carotid artery was ligated, and the nylon suture was inserted. Regional CBF was measured for $30 \mathrm{~min}$ after suture insertion.
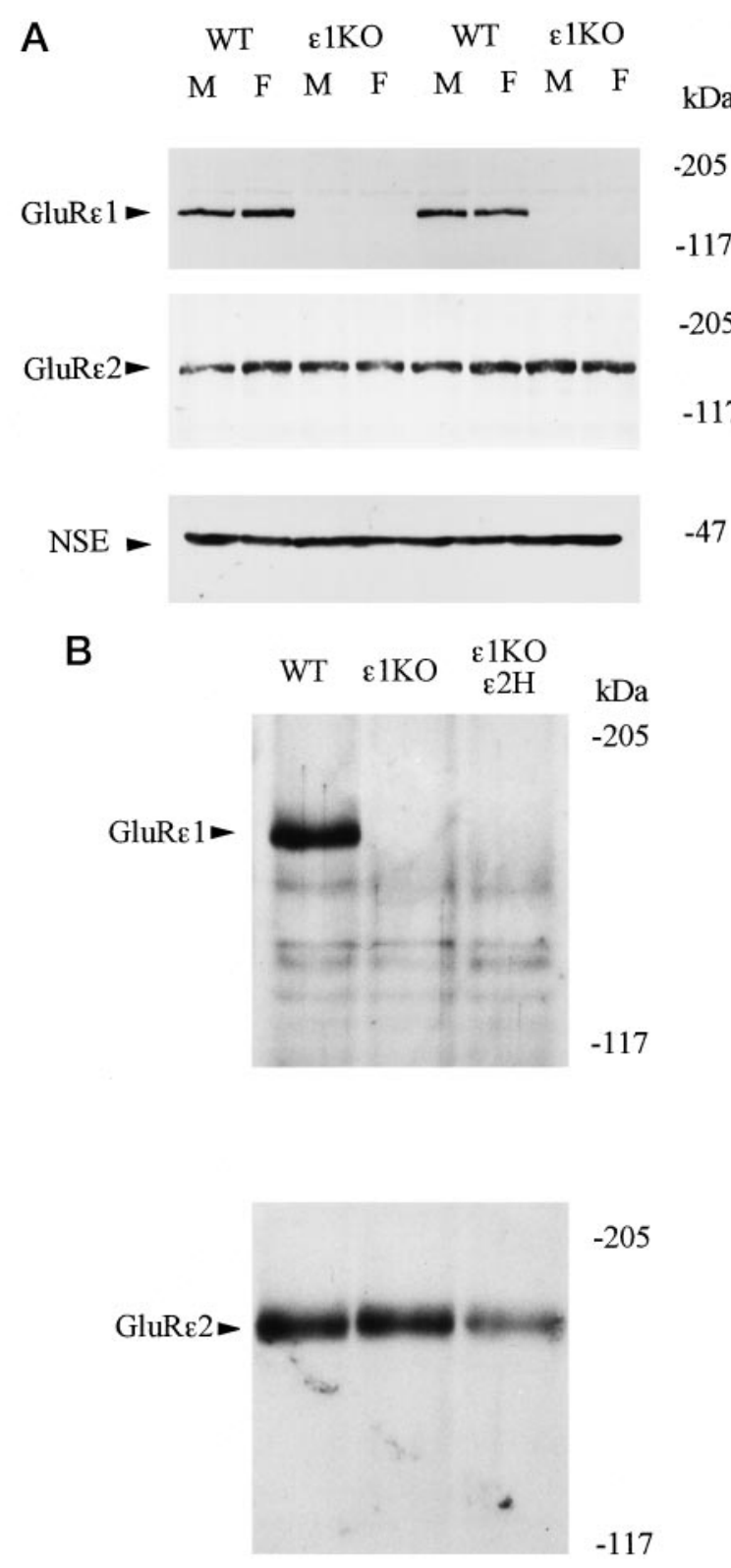

Figure 1. A, Western blot analysis of forebrain proteins from WT and $\epsilon 1 \mathrm{KO}$ mice with anti-GluR $\epsilon 1$ (top), anti-GluR $\epsilon 2$ (middle), and anti-NSE (bottom) antibodies. Samples from two males $(M)$ and two females $(F)$ of each genotype were presented. $B$, Western blot analysis of forebrain proteins from WT, $\epsilon 1 \mathrm{KO}$, and $\epsilon 1 \mathrm{KO} \epsilon 2 \mathrm{H}$ male mice with anti-GluR $\epsilon 1$ (top) and anti-GluR $\epsilon 2$ antibodies (bottom).

\section{RESULTS}

\section{Expression of the GluRe1 and GluRe2 subunit proteins in mutant mice}

We first examined the expression levels of GluR $\epsilon 1$ and GluR $\epsilon 2$ subunit proteins in the forebrain of the WT and mutant mice using Western blot analysis. The intensities of immunoreactive bands of GluR $\epsilon 1$ and GluR $\epsilon 2$ proteins were quantitatively analyzed and compared with those of NSE, a marker protein of neurons (Schmechel et al., 1978), as an internal standard. The amounts of GluR $\epsilon 1$ and GluR $\epsilon 2$ subunit proteins were comparable between male and female WT mice and between male and female $\epsilon 1 \mathrm{KO}$ mice, indicating that there was no appreciable 


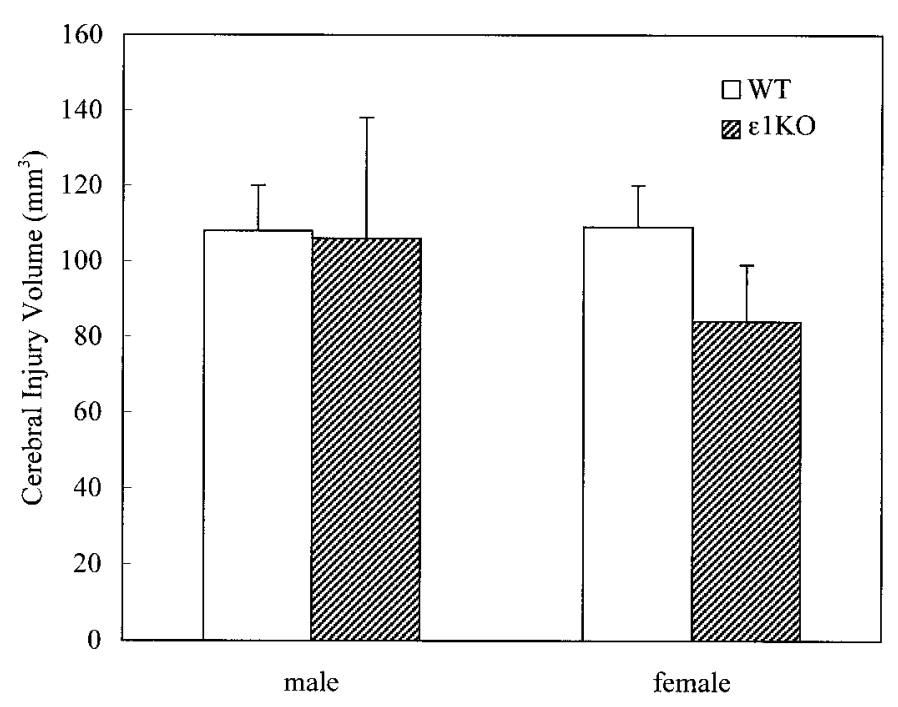

Figure 2. Cerebral injury volumes after permanent focal cerebral ischemia. There were no statistically significant differences in injury volumes between WT and $\epsilon 1 \mathrm{KO}$ mice in either males $(n=8$ and 4 for WT and $\epsilon 1 \mathrm{KO}$, respectively) or females ( $n=6$ and 9 for WT and $\epsilon 1 \mathrm{KO}$, respectively). Values are expressed as mean \pm SEM.

gender difference in the expression of GluR $\epsilon 1$ and GluR $\epsilon 2$ proteins (Fig. 1A). These analyses also confirmed the absence of GluR $\epsilon 1$ protein in $\epsilon 1 \mathrm{KO}$ and $\epsilon 1 \mathrm{KO} \epsilon 2 \mathrm{H}$ mice (Fig. $1 A, B$ ). The expression of GluR $\epsilon 2$ protein in $\epsilon 1 \mathrm{KO}$ mice was not appreciably affected by the GluR $\epsilon 1$ gene disruption, whereas the amount of GluR $\epsilon 2$ protein in $\epsilon 1 \mathrm{KO} \epsilon 2 \mathrm{H}$ mice was decreased to approximately half of that in WT littermates as reported previously (Fig. 1B) (Sakimura et al., 1995; Kutsuwada et al., 1996).

\section{Brain injury volumes after ischemia}

A total of 105 mice were subjected to focal cerebral ischemia by occluding the left middle cerebral artery using nylon filament. The brain injury volume after permanent focal cerebral ischemia was not significantly different between $\epsilon 1 \mathrm{KO}$ and WT mice $[91 \pm 14$ $(n=13)$ and $108 \pm 8(n=14) \mathrm{mm}^{3}$, respectively]. Although there was a trend toward smaller injury volumes in female $\epsilon 1 \mathrm{KO}$ mice, there was not a statistically significant difference between males and females (Fig. 2). Two male WT mice died at 19.5 and $16.5 \mathrm{hr}$ of ischemia, and their injury volumes were 149 and $141 \mathrm{~mm}^{3}$, respectively. There was not a premature mortality in $\epsilon 1 \mathrm{KO}$ mice.

After $2 \mathrm{hr}$ of transient focal ischemia, $\epsilon 1 \mathrm{KO}$ mice developed significantly smaller brain injury volumes compared with WT mice [41 $\pm 7(n=19)$ and $87 \pm 8(n=28) \mathrm{mm}^{3}$ for $\epsilon 1 \mathrm{KO}$ and WT, respectively; $p=0.0004$; unpaired $t$ test]. When the data were analyzed separately with regard to gender, the difference was more prominent in females $\left[30 \pm 9(n=7)\right.$ and $94 \pm 12(n=14) \mathrm{mm}^{3}$, respectively; $p=0.0039$; unpaired $t$ test] than in males [48 \pm 10 $(n=12)$ and $80 \pm 10(n=14) \mathrm{mm}^{3}$, respectively; $p=0.044$ unpaired $t$ test] (Fig. 3). There was, however, no statistically significant difference in injury volumes between males and female in either WT or $\epsilon 1 \mathrm{KO}$ mice. Five WT mice (one male and four females) died between 18 and $22 \mathrm{hr}$ of ischemia and had large injury volumes (between 135 and $187 \mathrm{~mm}^{3}$ ). On the other hand, there was no premature mortality in $\epsilon 1 \mathrm{KO}$ mice. The difference in mortality rate reached statistical significance when the data of the above two studies were combined ( $p<0.05 ; \chi^{2}$ test).

The injury volume in $\epsilon 1 \mathrm{KO} \epsilon 2 \mathrm{H}$ mice after $2 \mathrm{hr}$ of transient focal ischemia was similar to those of $\epsilon 1 \mathrm{KO}$ mice, and there was

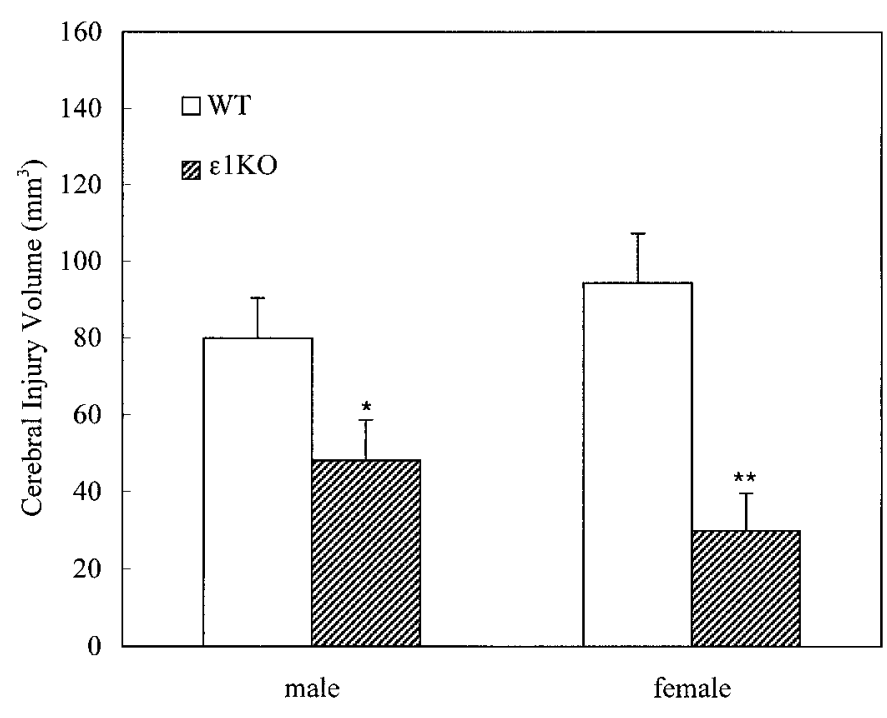

Figure 3. Cerebral injury volumes after $2 \mathrm{hr}$ of transient focal cerebral ischemia. $\epsilon 1 \mathrm{KO}$ mice had significantly smaller injury volume compared with WT littermate mice in both males $(n=14$ and 12 for WT and $\epsilon 1 \mathrm{KO}$, respectively; $\left.{ }^{*} p=0.044\right)$ and females $(n=14$ and 7 for WT and $\epsilon 1 \mathrm{KO}$, respectively; $* *=0.0039)$. Values are expressed as mean \pm SEM.

no additional reduction of injury volume by further disrupting one copy of the GluR $\epsilon 2$ subunit gene $[34 \pm 8(n=17)$ and $43 \pm$ $9(n=14) \mathrm{mm}^{3}$ for $\epsilon 1 \mathrm{KO} \epsilon 2 \mathrm{H}$ and $\epsilon 1 \mathrm{KO}$, respectively] (Fig. 4). One male $\epsilon 1 \mathrm{KO} \epsilon 2 \mathrm{H}$ mouse died at $22 \mathrm{hr}$ of ischemia and had an injury volume of $28 \mathrm{~mm}^{3}$. There was no premature mortality in $\epsilon 1 \mathrm{KO}$ mice.

When the injury size was examined in 2-mm-thick consecutive slices, the reduction of ischemic injury in mutant mice compared with WT mice was evident in all five slices $(p<0.01$; one-way ANOVA, followed by Fisher's PLSD test) (Fig. $5 A$ ). Notably, the attenuation of injury was more evident in the dorsolateral cerebral cortex, which is the area of milder ischemia called "ischemic penumbra" (Fig. 5B,C).

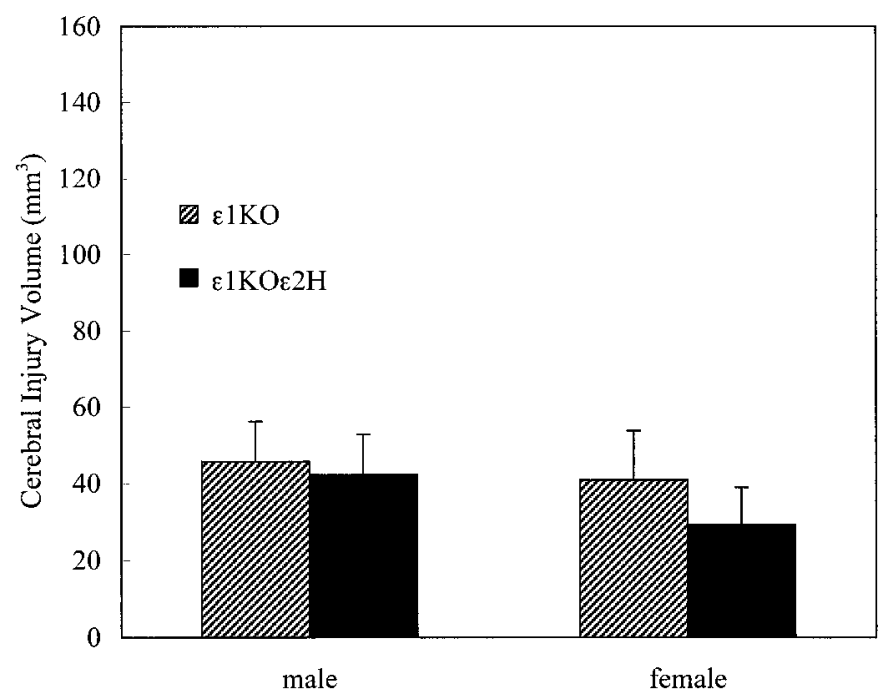

Figure 4. Cerebral injury volumes after $2 \mathrm{hr}$ of transient focal cerebral ischemia compared with $\epsilon 1 \mathrm{KO} \epsilon 2 \mathrm{H}$ mice and their littermates $\epsilon 1 \mathrm{KO}$. There were no significant differences between these two groups in either males $(n=6$ each) or females $(n=8$ and 11 for $\epsilon 1 \mathrm{KO}$ and $\epsilon 1 \mathrm{KO} \epsilon 2 \mathrm{H}$, respectively). Values are expressed as mean \pm SEM. 

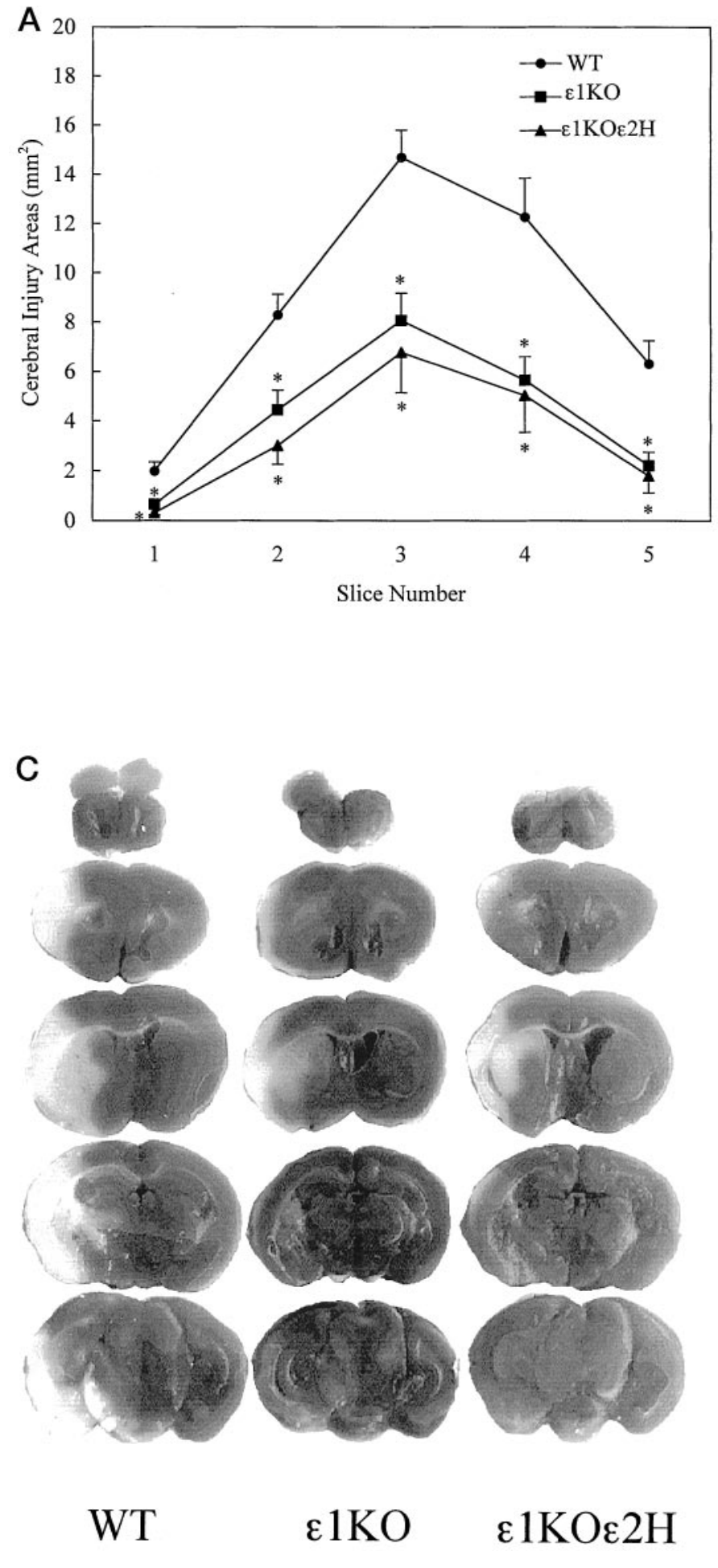

\section{Regional CBF after brain ischemia}

To exclude the possibility that gene disruptions could cause different $\mathrm{CBF}$ after middle cerebral artery occlusion, which could influence the results, we measured regional CBF before and after the occlusion in a separate set of animals ( $n=5$ in each group). Regional CBF at dorsolateral cerebral cortex, as measured continuously by laser-Doppler flowmetry, demonstrated reduction of $\mathrm{CBF}$ by $\sim 35 \%$ when common carotid artery was occluded. The CBF further decreased to $\sim 17 \%$ of baseline after insertion of the nylon suture, which recovered and remained at a level of $\sim 22 \%$ of
B

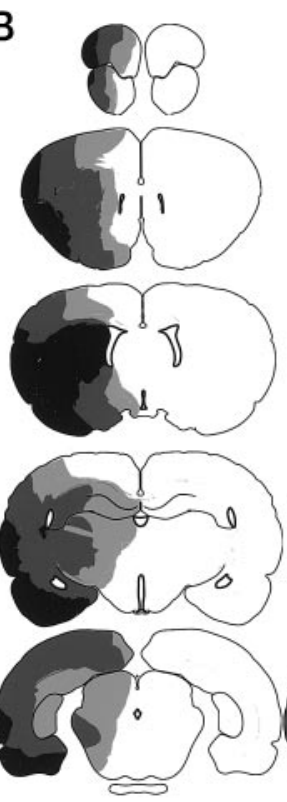

WT

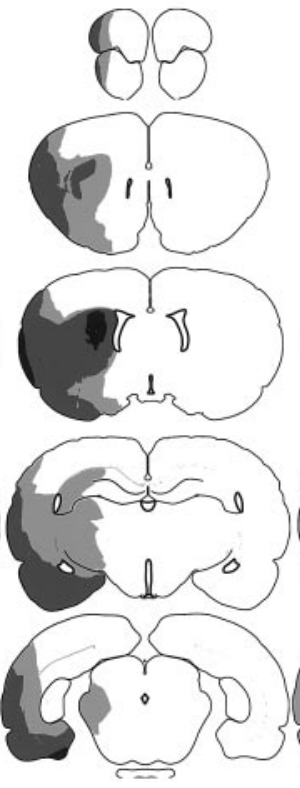

$\varepsilon 1 \mathrm{KO}$

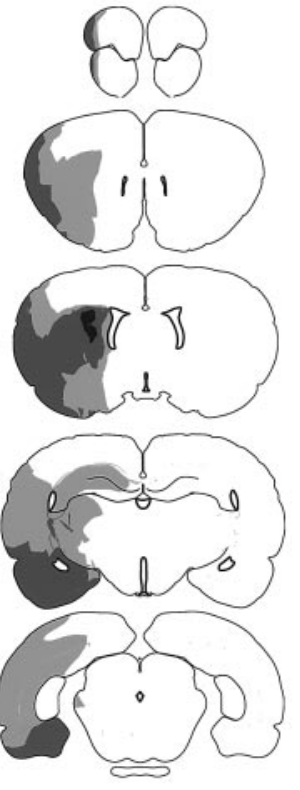

$\varepsilon 1 \mathrm{KO} 2 \mathrm{H}$
Figure 5. A, Areas of cerebral injury on each brain slice after $2 \mathrm{hr}$ of transient focal cerebral ischemia. Data from two experiments are combined $[\epsilon 1 \mathrm{KO}(n=33), \epsilon 1 \mathrm{KO} \epsilon 2 \mathrm{H}(n=17)$, and WT $(n=28)]$. Reduction of injury area was observed on all the brain slices in $\epsilon 1 \mathrm{KO}$ and $\epsilon 1 \mathrm{KO} \epsilon 2 \mathrm{H}$ mice compared with WT ( $p<0.01$; one-way ANOVA, followed by Fisher's PLSD test). Values are expressed as mean \pm SEM. B, Spatial distribution of injury areas on five brain slices. Black areas indicate regions of brain injury observed in most of the animals $(>70 \%)$ in the group. Dark gray and light gray areas demonstrate regions of injury observed less frequently (40-70 and 20-40\%, respectively). C, Representative scanned images of TTC-stained brain slices analyzed for injury volume. White areas indicate regions of tissue injury. Calculated injury volumes for these particular animals were 100,39 , and $35 \mathrm{~mm}^{3}$ for $\mathrm{WT}, \epsilon 1 \mathrm{KO}$, and $\epsilon 1 \mathrm{KO} \epsilon 2 \mathrm{H}$, respectively.

baseline during the first 30 min without any significant difference between the two groups (Fig. 6). Thus, the reduction in ischemic injury volumes was not attributable to the regional CBF differences in the dorsolateral cerebral cortex, or ischemic penumbra, in the acute stage.

\section{DISCUSSION}

The present investigation clearly demonstrates for the first time that mice lacking the GluR $\epsilon 1$ subunit of NMDA receptor channel are less prone to cerebral injury after focal brain ischemia. 


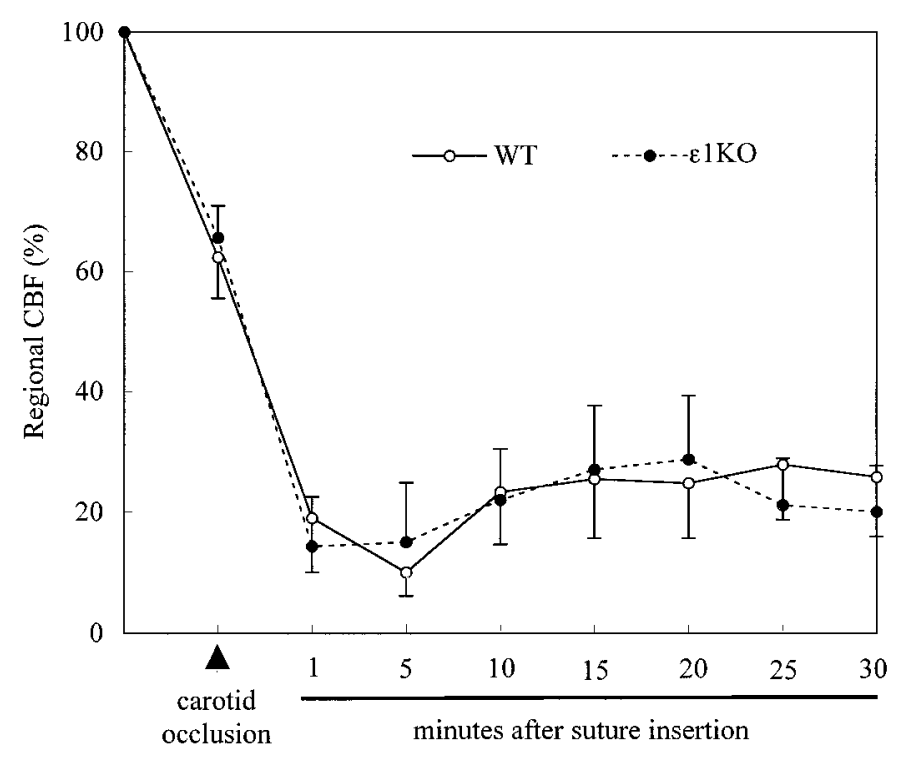

Figure 6. Regional CBF profiles measured at dorsolateral cerebral cortex using laser-Doppler flowmetry after vessel occlusion in WT $(n=5)$ and $\epsilon 1 \mathrm{KO}(n=5)$ mice. Values are expressed as mean \pm SEM. Regional CBF was reduced by $\sim 35 \%$ of baseline after common carotid artery occlusion. Insertion of the nylon suture resulted in further reduction of the CBF to $\sim 20 \%$ of baseline for $30 \mathrm{~min}$. No significant differences were detected in CBF between $\epsilon 1 \mathrm{KO}$ and WT mice.

Functional NMDA receptor channel complexes contain both GluR $\zeta$ and GluR $\epsilon$ subunits. In the forebrain of mature mice, GluR $\epsilon$ constituents making up the hetero-oligomeric receptors are primarily the GluR $\epsilon 1$ and GluR $\epsilon 2$ subunits (Watanabe et al., 1992). Western blot analyses in this study confirmed that the targeted disruption of the GluR $\epsilon 1$ subunit gene resulted in complete absence of GluR $\epsilon 1$ subunit protein in the brain homogenate and that there was no compensatory increase in the content of GluR $\epsilon 2$ subunit protein. In fact, the NMDA receptor channel activity in the hippocampal CA1 region of $\epsilon 1 \mathrm{KO}$ mice is decreased to about half of that of WT mice, and correspondingly, thresholds for hippocampal LTP induction and contextual learning are increased (Sakimura et al., 1995; Kiyama et al., 1998). Thus, a straightforward explanation of our results will be that the decrease in the number of functional NMDA receptor channels on the cell membrane of forebrain neurons in $\epsilon 1 \mathrm{KO}$ mice has made cells more resistant to glutamate-induced neurotoxicity. Consistent with this, it was reported that the suppression of GluR $\zeta 1$ subunit synthesis by administrating antisense oligodeoxynucleotides reduced infarction volumes produced by focal brain ischemia (Wahlestedt et al., 1993).

This explanation implies that the another constituent of NMDA receptor channels, the GluR $\epsilon 2$ subunit, would also be involved in glutamate-induced neurotoxicity. In agreement with this, it is demonstrated that selective GluR $\epsilon 2$ subunit antagonist provides brain protection in feline brain ischemia (Di et al., 1997). In our study, however, further disruption of one copy of the GluR $\epsilon 2$ subunit gene in $\epsilon 1 \mathrm{KO}$ mice $(\epsilon 1 \mathrm{KO} \epsilon 2 \mathrm{H}$ mice) appeared to have no additional protective effects against ischemia. It is possible that the extent of reduction in GluR $\epsilon 2$ subunit protein may not be significant enough to bring additional protective effects already bestowed by complete deletion of the GluR $\epsilon 1$ gene.

Alternatively, the GluR $\epsilon 1$ subunit may indeed play a more pivotal role in glutamate neurotoxicity than the GluR $\epsilon 2$ subunit. Interestingly, in this regard, it is demonstrated that vulnerability of CA1 neurons to glutamate is intrinsically less in newborns and more in 3-week-old rats, suggesting that the expression of the GluR $\epsilon 1$ subunit, whose expression occurs postnatally, increases the glutamate neurotoxicity (Marks et al., 1996).

Differences in gating and pharmacological properties, as well as in various modulations, are noted between GluR $\epsilon 1 / \zeta 1$ and

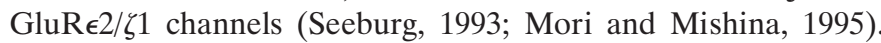
Calcium-dependent inactivation of NMDA receptor channels, observed in the cultured hippocampal neurons (Legendre et al., 1993), is shown to be subunit-specific, requires the presence of the GluR $\epsilon 1$ subunit, and is less pronounced in GluR $\epsilon 2$ subunitcontaining heteromers (Krupp et al., 1996). The offset decay time constant of the GluR $\epsilon 1 / \zeta 1$ channel is $\sim 120 \mathrm{msec}$ and that of the GluR $\epsilon 2 / \zeta 1$ channel is $\sim 400 \mathrm{msec}$ (Monyer et al., 1994). The duration of NMDA receptor channel-mediated EPSCs in neurons of the visual cortex layer IV and superior colliculus is longer at early developmental stages and becomes progressively shorter (Hestrin, 1992; Carmignoto and Vicini, 1992). Neurons of postnatal neocortex expressing the GluR $\epsilon 1$ subunit have faster EPSCs, and the proportion of cells expressing this subunit increases developmentally (Flint et al., 1997). The absence of the GluR $\epsilon 1$ subunit, therefore, would lead to qualitative changes of NMDA receptor channel functions in the brain. In fact, alterations in NMDA receptor channel properties have been demonstrated in $\epsilon 1 \mathrm{KO}$ mice. In cerebellar granule cells, the decay time course of NMDA receptor-mediated EPSCs was slower in the mutants compared with WT (Takahashi et al., 1996). In hippocampal CA3 pyramidal neurons, reduction in the NMDA receptor-mediated EPSCs was observed selectively at the synapses formed by commissural-associational inputs (Ito et al., 1997). These differences between GluR $\epsilon 1$ and GluR $\epsilon 2$ heteromers in receptor channel functions, however, do not necessarily support the hypothesis that the GluR $\epsilon 1$ subunit is more involved in neurotoxicity than the GluR $\epsilon 2$ subunit.

Although glutamate neurotoxicity has been implicated as a major mechanism of ischemic brain injury (Choi, 1988; Lipton and Rosenberg, 1994), the effects of antagonists directed against NMDA receptors have been unsatisfactory in clinical trials (Lipton, 1993; Schehr, 1996), as well as in experimental animals (Buchan and Pulsinelli, 1990). In the current study, significant reduction in injury volume was observed in the GluR $\epsilon 1$ subunitdeficient mice in transient brain ischemia but not in permanent ischemia in which only a trend toward smaller injury volume was observed in females. It is also noted that the attenuation of tissue injury was predominantly in the so-called ischemic penumbra and was less in the core region. Thus, the resistance provided by the GluR $\epsilon 1$ subunit ablation was prominent in mild to moderate ischemia but less so in severe ischemic insult. This is in accordance with the notion that mechanisms other than the NMDA receptor-mediated type may become dominant in severe brain ischemia (Siesjo, 1992). It is hypothesized that brain ischemia induces downregulation of the GluR2 subunit of AMPA receptors, which renders AMPA receptor channels permeable to calcium and, consequently, increases glutamate-induced neurotoxicity after ischemia (Pellegrini-Giampietro et al., 1992; Gorter et al., 1997). Our results, however, indicate significant involvement of the NMDA receptor channel-mediated neurotoxicity in focal cerebral ischemia and reperfusion.

Although it has been demonstrated that estrogens attenuate excitotoxic injury (Goodman et al., 1996) and also upregulate NMDA receptors (Woolley et al., 1997), which may exacerbate glutamate-induced neurotoxicity, statistically significant gender 
difference was not observed in the current study in terms of ischemic injury. There was not a significant gender difference in the amounts of GluR $\epsilon 1$ and GluR $\epsilon 2$ subunit proteins in brain homogenate taken from WT or $\epsilon 1 \mathrm{KO}$ mice, either. In any case, our data demonstrate direct evidence that NMDA receptor channels, specifically the GluR $\epsilon 1$ subunit, play a major role in ischemic brain injury in both males and females.

\section{REFERENCES}

Bederson JB, Pitts LH, Germano SM, Nishimura MC, Davis RL, Bartkowski HM (1986) Evaluation of 2,3,5-triphenyltetrazolium chloride as a stain for detection and quantification of experimental cerebral infarction in rats. Stroke 17:1304-1308.

Buchan A, Pulsinelli WA (1990) Hypothermia but not the $N$-methyl-Daspartate antagonist, MK-801, attenuates neuronal damage in gerbils subjected to transient global ischemia. J Neurosci 10:311-316.

Carmignoto G, Vicini S (1992) Activity-dependent decrease in NMDA receptor responses during development of the visual cortex. Science 258:1007-1011.

Choi DW (1988) Glutamate neurotoxicity and diseases of the nervous system. Neuron 1:623-634.

Di X, Bullock R, Watson J, Fatouros P, Chenard B, White F, Corwin F (1997) Effect of CP101,606, a novel NR2B subunit antagonist of the $N$-methyl-D-aspartate receptor, on the volume of ischemic brain damage and cytotoxic brain edema after middle cerebral artery occlusion in the feline brain. Stroke 28:2244-2251.

Flint AC, Maisch US, Weishaupt JH, Kriegstein AR, Monyer H (1997) NR2A subunit expression shortens NMDA receptor synaptic currents in developing neocortex. J Neurosci 17:2469-2476.

Forrest D, Yuzaki M, Soares HD, Ng L, Luk DC, Sheng M, Stewart CL, Morgan JI, Connor JA, Curran T (1994) Targeted disruption of NMDA receptor 1 gene abolishes NMDA response and results in neonatal death. Neuron 13:325-338.

Goodman Y, Bruce AJ, Cheng B, Mattson MP (1996) Estrogens attenuate and corticosterone exacerbates excitotoxicity, oxidative injury, and amyloid beta-peptide toxicity in hippocampal neurons. J Neurochem 66:1836-1844.

Gorter JA, Petrozzino JJ, Aronica EM, Rosenbaum DM, Opitz T, Bennett MVL, Connor JA, Zukin RS (1997) Global ischemia induces downregulation of Glur2 mRNA and increases AMPA receptormediated $\mathrm{Ca}^{2+}$ influx in hippocampal CA1 neurons of gerbil. J Neurosci 17:6179-6188.

Hestrin S (1992) Developmental regulation of NMDA receptormediated synaptic currents at a central synapse. Nature 357:686-689.

Huang Z, Huang PL, Panahian N, Dalkara T, Fishman MC, Moskowitz MA (1994) Effects of cerebral ischemia in mice deficient in neuronal nitric oxide synthase. Science 265:1883-1885.

Ito I, Futai K, Katagiri H, Watanabe M, Sakimura K, Mishina M, Sugiyama H (1997) Synapse-selective impairment of NMDA receptor functions in mice lacking NMDA receptor $\epsilon 1$ or $\epsilon 2$ subunit. J Physiol (Lond) 500:401-408.

Kiyama Y, Manabe T, Sakimura K, Kawakami F, Mori H, Mishina M (1998) Increased thresholds for long-term potentiation and contextual learning in mice lacking the NMDA-type glutamate receptor $\epsilon 1$ subunit. J Neurosci 18:6704-6712.

Krupp JJ, Vissel B, Heinemann SF, Westbrook GL (1996) Calciumdependent inactivation of recombinant $N$-methyl-D-aspartate receptors is NR2 subunit specific. Mol Pharmacol 50:1680-1688.

Kutsuwada T, Sakimura K, Manabe T, Takayama C, Katakura N, Kushiya E, Natsume R, Watanabe M, Inoue Y, Yagi T, Aizawa S, Arakawa M, Takahashi T, Nakamura Y, Mori H, Mishina M (1996) Impairment of suckling response, trigeminal neuronal pattern formation, and hippocampal LTD in NMDA receptor $\epsilon 2$ subunit mutant mice. Neuron 16:333-344.

Legendre P, Rosenmund C, Westbrook GL (1993) Inactivation of
NMDA channels in cultured hippocampal neurons by intracellular calcium. J Neurosci 13:674-684.

Li Y, Erzurumlu RS, Chen C, Jhaveri S, Tonegawa S (1994) Whiskerrelated neuronal patterns fail to develop in the trigeminal brainstem nuclei of NMDAR1 knockout mice. Cell 76:427-437.

Lipton SA (1993) Prospects for clinically tolerated NMDA antagonists: open-channel blockers and alternative redox state of nitric oxide. Trends Neurosci 16:527-532.

Lipton SA, Rosenberg PA (1994) Excitatory amino acids as a final common pathway for neurologic disorders. N Engl J Med 330:613-622.

Marks JD, Friedman JE, Haddad GG (1996) Vulnerability of CA1 neurons to glutamate is developmentally regulated. Brain Res Dev Brain Res 97:194-206.

Monyer H, Burnashev N, Laurie DJ, Sakmann B, Seeburg PH (1994) Developmental and regional expression in the rat brain and functional properties of four NMDA receptors. Neuron 12:529-540.

Mori H, Mishina M (1995) Structure and function of the NMDA receptor channel. Neuropharmacology 34:1219-1237.

Morikawa E, Zhang S-M, Seko Y, Toyoda T, Kirino T (1996) Treatment of focal cerebral ischemia with synthetic oligopeptide corresponding to lectin domain of selectin. Stroke 27:951-956.

Nakanishi S (1992) Molecular diversity of glutamate receptors and implications for brain function. Science 258:597-603.

Pellegrini-Giampietro DE, Zukin RS, Bennet MVL, Cho S, Pulsinelli WA (1992) Switch in glutamate receptor subunit gene expression in CA1 subfield of hippocampus following global ischemia in rats. Proc Natl Acad Sci USA 89:10499-10503.

Sakimura K, Yoshida Y, Nabeshima Y, Takahashi Y (1980) Biosynthesis of the brain-specific 14-3-2 protein in a cell-free system from wheat germ extract directed with poly(A)-containing RNA from rat brain. J Neurochem.34:687-693.

Sakimura K, Kutsuwada T, Ito I, Manabe T, Takayama C, Kushiya E, Yagi T, Aizawa S, Inoue Y, Sugiyama H, Mishina M (1995) Reduced hippocampal LTP and spatial learning in mice lacking NMDA receptor $\epsilon 1$ subunit. Nature 373:151-155.

Schehr RS (1996) New treatments for acute stroke. Nat Biotechnol 14:1549-1554.

Schmechel D, Marangos PJ, Zis AP, Brightman M, Goodwin FK (1978) Brain enolases as specific markers of neuronal and glial cells. Science 199:313-315.

Seeburg PH (1993) The molecular biology of mammalian glutamate receptor channels. Trends Neurosci 16:359-365.

Siejo BK (1992) Pathophysiology and treatment of focal cerebral ischemia. Part II: mechanisms of damage and treatment. J Neurosurg 77:337-354.

Takahashi T, Feldmeyer D, Suzuki N, Onodera K, Cull-Candy SG, Sakimura K, Mishina M (1996) Functional correlation of NMDA receptor $\epsilon$ subunits expression with the properties of single-channel and synaptic currents in the developing cerebellum. J Neurosci 16:4376-4382.

Wahlestedt C, Golanov E, Yamamoto S, Yee F, Ericson H, Yoo H, Inturrisi CE, Reis DJ (1993) Antisense oligodeoxynucleotides to NMDA-R1 receptor channel protect cortical neurons from excitotoxicity and reduce focal ischaemic infarctions. Nature 363:260-263.

Watanabe M, Inoue Y, Sakimura K, Mishina M (1992) Developmental changes in distribution of NMDA receptor channel subunit mRNAs. NeuroReport 3:1138-1140.

Watanabe M, Fukaya M, Sakimura K, Manabe T, Mishina M, Inoue Y (1998) Selective scarcity of NMDA receptor channel subunits in the stratum lucidum (mossy fiber-recipient layer) of the hippocampal CA3 subfield. Eur J Neurosci 10:478-487.

Woolley CS, Weiland NG, McEwen BS, Schwartzkroin PA (1997) Estradiol increases the sensitivity of hippocampal CA1 pyramidal cells to NMDA receptor-mediated synaptic input: correlation with dendritic spine density. J Neurosci 17:1848-1859. 